\title{
Enhancing innovative delivery
}

\section{in schools using design thinking [version 1; peer review: 2}

\section{approved with reservations]}

\author{
Sharmini Gopinathan (iD), Anisha Haveena Kaur¹, Kanesaraj Ramasamy (iD2, \\ Murali Raman ${ }^{3}$ \\ ${ }^{1}$ Faculty of Management, Multimedia University, Cyberjaya, Selangor, 63000, Malaysia \\ 2Faculty of Computing \& Informatics, Multimedia University, Cyberjaya, Selangor, 63000, Malaysia \\ ${ }^{3}$ Research \& Innovation, Asia Pacific University, Jalan Teknologi 5, Taman Teknologi Malaysia, 57000, Malaysia
}

V1 First published: 15 Sep 2021, 10:927

https://doi.org/10.12688/f1000research.72860.1

Second version: 30 Nov 2021, 10:927

https://doi.org/10.12688/f1000research.72860.2

Latest published: 10 Jan 2022, 10:927

https://doi.org/10.12688/f1000research.72860.3

\section{Abstract}

The pandemic has created challenges in all sectors of the economy and education. Traditional teaching approaches seem futile in the new context, thus the need to constantly reinvent the delivery to meet the fast-paced changes in the education domain. Hence, Design Thinking (DT) is an alternative approach that might be useful in the given context. DT is known to be a human-centric approach to innovative problem-solving processes. DT could be employed in the delivery process to develop twenty-first-century skills and enhance creativity and innovation, in an attempt to identify alternative solutions. The study explores the role of design thinking (DT) mindset in innovative delivery among teachers. It enhances and facilitates innovative content delivery by leveraging creativity. The study targeted 131 teachers from primary and secondary schools in Malaysia. Data was collected through an online survey and was analyzed using SmartPLS to establish relationships between DT and Innovative Delivery in schools. The data was further analyzed to seek co-relations between the DT steps and the successful transformation of content delivery by teachers. The study established a framework for the application of design thinking for teachers as the primary support in developing activities for their students. The outcome of this study will help fill the gap towards creating an interesting method of delivery in schools and constantly innovating the method to suit the evolving generation. It provides an in-depth reason as to why students are not interested in the teacher's lessons which, in turn, affects their performance. This insight is crucial for the Ministry of Education and policymakers to enhance teachers' ability to innovatively deliver content to students.

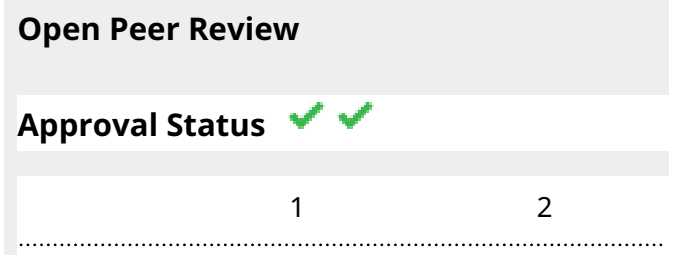

version 3

(revision)

10 Jan 2022

version 2

(revision)

30 Nov 2021

version 1

15 Sep 2021
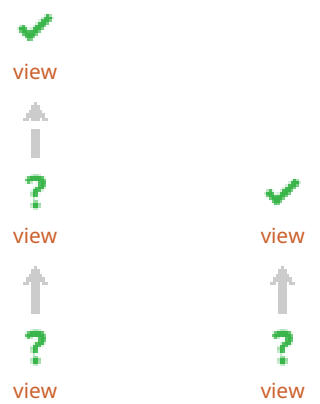

1. Paulo SImeão Carvalho ID, University of Porto, Porto, Portugal

2. Achmad Samsudin ID, Universitas

Pendidikan Indonesia, Bandung, Indonesia Any reports and responses or comments on the article can be found at the end of the article. 


\section{Keywords}

Design thinking, innovative teaching, 21st-century teaching, Malaysian

schools, innovative delivery

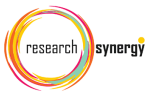

This article is included in the Research Synergy

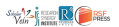

Foundation gateway.

Corresponding author: Sharmini Gopinathan (sharmini.gopinathan@mmu.edu.my)

Author roles: Gopinathan S: Conceptualization, Formal Analysis, Methodology, Project Administration, Supervision; Kaur AH: Data Curation, Formal Analysis, Investigation, Validation, Writing - Original Draft Preparation; Ramasamy K: Data Curation, Resources, Validation, Writing - Review \& Editing; Raman M: Data Curation, Supervision, Visualization, Writing - Review \& Editing

Competing interests: No competing interests were disclosed.

Grant information: The author(s) declared that no grants were involved in supporting this work.

Copyright: (c) 2021 Gopinathan S et al. This is an open access article distributed under the terms of the Creative Commons Attribution License, which permits unrestricted use, distribution, and reproduction in any medium, provided the original work is properly cited.

How to cite this article: Gopinathan $\mathrm{S}$, Kaur AH, Ramasamy $\mathrm{K}$ and Raman M. Enhancing innovative delivery

in schools using design thinking [version 1; peer review: 2 approved with reservations] F1000Research 2021, 10:927

https://doi.org/10.12688/f1000research.72860.1

First published: 15 Sep 2021, 10:927 https://doi.org/10.12688/f1000research.72860.1 


\section{Introduction}

We are living in unprecedented times. The COVID-19 pandemic coupled with the continuous onslaught of digital technologies has acerbated the level of volatility, uncertainty, complexity, and ambiguity (VUCA), across various sectors. The education sector is not spared and remains a target for greater industrial shifts and repositioning in the context of remaining relevant. To this end, even schools are subject to changes-failure to innovate and offer the state of curriculum and pedagogy puts extreme pressure on students in their quest to become employable at later parts of life. As such, to ensure the education systems keep abreast with changes, strategic and practical shifts in the delivery of educational content is crucial. Failure to do so could result in longer term socioeconomic consequences.

In this paper, we posit that innovative delivery of educational content is required to ensure students can truly benefit from the learning outcomes set out in schools. Therefore, we propose precursors such as having empathy, rejuvenated thinking process, curriculum enhancement and gamification of lessons that can lead to innovative delivery of lessons. This includes examining the role of design thinking (DT) in generating innovative delivery of educational content.

There are various definitions of design thinking. According to Oxford Languages", the word 'design', a noun, refers to "a plan or drawing produced to show the look and function or workings of a building, garment, or other objects before it is made". This definition implies that 'design' relates to any form of idea that is put forth either in the form of sketch, model, or better still as a full-blown prototype before the final product or model is developed. The second word, 'thinking', a noun, refers to "the process of considering or reasoning about something," according to Oxford Languages ${ }^{2}$. The keywords based on this definition are reasoning and process. DT therefore can be defined as a systematic or a structured approach to developing something, initially as a model or prototype, before a final version is built. We need to understand nevertheless that when people build or develop something, it is often done to solve a real-world problem. As such, DT is often defined as a systematic and structured approach to solving a problem based on design.

The inherent ideas beneath DT are not new. Nevertheless, DT presents an organised way of including innovative thinking and creativity in organisations. To be able to derive the inspirational values of DT, highly specific tools and techniques are used that are usually presented in a simplified manner. DT is able to solve problems using a user-centric collaborative method ${ }^{3}$. Stanford University's design school (dSchool) established a five-step DT process ${ }^{4}$, which is summarised in Table 1.

DT when institutionalised as an inherent culture in schools, could lead to innovative teaching and learning processes. Specifically, DT has the potential to cultivate empathy, lead to a growth mindset (new thinking processes), and lead to curriculum enhancement in the form of gamified learning.

\section{Empathy}

Empathy as a core of every DT project, one outcome of successful DT applications is the ability to encourage a culture that gives everybody a chance to express themselves freely. Empathy in the classroom context refers to the teacher-student interaction. Empathy shows the connection of what a teacher thinks or knows about their students and what they do to provide the necessary response to the students' needs ${ }^{5}$. This is also needed as teachers are the ones who arrange learning experiences for their students. Teachers are able to do so by providing feedback to their students. According to Mueller and Dweck ${ }^{6}$, students who are praised and given feedback based on their efforts (instead of intelligence) are more likely to show an interest in mastery and tend to seek challenges when attempting to achieve their learning goals. These students can think out of the box as they are under the impression that their performances can be improved?

\section{Thinking process}

Innovative and creative thinking is the product of DT's ideation. The thinking process closely relates to the Growth Mindset Theory by Dweck ${ }^{8}$. Students with a growing mindset tend to learn through persistence, failure, and different strategies.

\section{Table 1. Phases of design thinking based on the understanding of Stanford School.}

\begin{tabular}{|l|l|}
\hline DT Phase & \multicolumn{1}{c|}{ Brief Explanation } \\
\hline Empathy & $\begin{array}{l}\text { The most vital step in DT. Design thinkers are given a design challenge to understand the emotional attachment and pain } \\
\text { points of customers towards a problem or challenge. The findings from this step will naturally lead to the second step called } \\
\text { 'define'. }\end{array}$ \\
\hline Define & $\begin{array}{l}\text { This step requires design thinkers to focus on getting deep into the problem from the customer's viewpoint. They will } \\
\text { then spend some time to come up with specific perspectives. In addition, they will also suggest some game-changing } \\
\text { propositions to the problem based on insights or intuitions. }\end{array}$ \\
\hline Ideate & $\begin{array}{l}\text { This step allows design thinkers to come up with as many ideas as they can in order to address the issue or problem which } \\
\text { has been defined. Ideate is similar to brainstorming sessions. }\end{array}$ \\
\hline Prototype & $\begin{array}{l}\text { The step where ideas are translated into tangible manifestations. The prototype may not necessarily be a tangible product } \\
\text { as it could also be a simulation, campaign, or mockup (this depends on the challenge at hand). }\end{array}$ \\
\hline Test & $\begin{array}{l}\text { This final step in DT emphasises on the importance of pitching the idea to indemnified target groups. This is followed by } \\
\text { the gathering of feedback. The solution is either launched to the market or is reworked until it is deemed to be suitable for } \\
\text { market launch. }\end{array}$ \\
\hline
\end{tabular}


Additionally, students are able to overcome challenges given to them by practicing and using setbacks as a form of motivation. Implementation of innovative teaching strategies such as collaborative learning, using real-life problems to address issues, and experimentation also contribute to the thinking process 9 . According to the Cambridge Learning Attributes Guide $^{10}$, the thinking process is a powerful tool which not only requires knowledge and understanding of a subject matter but also the students' willingness to question it. By ensuring that students are provided with materials that enable them to challenge the subject matter they will be able to express their own understanding and opinions on it.

\section{Gamifying lessons}

Prototyping in DT leads to a new form of learning, which in this context refers to gamification. Gamifying lessons enables teachers to establish a casual learning environment whereby students are able to challenge themselves via fun online games $^{11}$. According to Hakak et al. ${ }^{12}$, students are given tasks or "missions" with varying levels of difficulty and they are required to complete them within a short time frame. They are also given the chance to repeat the "mission" if they fail to achieve the goal. This allows students to analyse and correct the mistakes made, which in turn encourages them to build a positive attitude towards learning ${ }^{13}$. Eleftheria et al. ${ }^{14}$ believe that the use of gamification provides students with a comprehensive understanding of the subject being taught and it increases their engagement and enjoyment in the learning process.

\section{Curriculum enhancement}

Curriculum enhancement is the product of testing from DT. The materials provided in an enhanced curriculum should allow students to deeply reflect the topic at hand and provide them with the opportunities to make connections between other subjects and topics as well ${ }^{10}$. Additionally, the curriculum should look beyond testing. Assessments in the form of evaluating students' points of view and their observations are important as this shows the process of their progression ${ }^{15}$. Teachers are also advised to consider implementing more group work and interactive lessons which builds on what students already know. From there, students are able to apply existing knowledge and add value to new knowledge.

As such, this paper aims to answer the following research questions:

1. Is there a relationship between DT and innovative delivery of teaching content in schools, specifically using the stage called empathy?

2. In addition to DT and empathy, what role does new thinking process, curriculum enhancement and gamification of lessons play towards similar aspirations?

Hence, the fulcrum of the study's objectives is:

1. To determine if DT in the form of empathy leads to innovative delivery of curriculum

2. To examine if DT can lead to new forms of thinking processes and thus lead to innovative delivery of curriculum

3. To assess whether DT does lead to innovative delivery of curriculum, by promoting curriculum enhancement and gamified approach to teaching and learning.

\section{Methods}

This research is purely quantitative whereby online survey was used as a means of data collection. Table 2 depicts the design

\section{Table 2. Research design elements.}

\begin{tabular}{|c|c|c|}
\hline $\begin{array}{l}\text { Research Design } \\
\text { Component }\end{array}$ & Description & Rationalisation \\
\hline Nature of Study & Exploratory & $\begin{array}{l}\text { The premise of this research is to determine whether design thinking leads to innovative delivery of } \\
\text { lessons, especially in primary and secondary schools in Malaysia, as there is inadequate research in } \\
\text { this particular domain of study. }\end{array}$ \\
\hline Role of Theory & $\begin{array}{l}\text { To test the } \\
\text { theory }\end{array}$ & $\begin{array}{l}\text { A deductive approach was employed for this study to test the hypothetical framework, namely the } \\
\text { role of empathy, thinking process, curriculum enhancement and gamifying lessons in enhancing } \\
\text { innovative delivery. }\end{array}$ \\
\hline Sampling Process & $\begin{array}{l}\text { Purposive } \\
\text { sampling }\end{array}$ & $\begin{array}{l}\text { A list of all primary and secondary public schools under the Ministry of Education Malaysia was attained } \\
\text { by the researchers. The schools for this research were chosen based on Excel's RAND (random) } \\
\text { function. The contact information of the teachers from the selected schools were attained from the } \\
\text { National Union of the Teaching Profession (NUTP) as well as from the headmasters of those schools. }\end{array}$ \\
\hline $\begin{array}{l}\text { Data Collection } \\
\text { Technique }\end{array}$ & Surveys & $\begin{array}{l}\text { Due to the current COVID-19 outbreak, the questionnaire was prepared using Google Forms and } \\
\text { was distributed to the primary and secondary public-school teachers via email, WhatsApp, and social } \\
\text { media. A minimum of } 129 \text { respondents are required as per the G*Power analysis, } 131 \text { responses } \\
\text { were collected at the end of the data collection period of one month. After data cleaning was } \\
\text { conducted, there were no representation of teachers from the states of Perlis and Johore as well as } \\
\text { the Federal Territory of Labuan. The teachers were not reachable/contactable due to the Movement } \\
\text { Control Order (MCO) implemented by the government of Malaysia to curb the spread of COVID-19. } \\
\text { Thus, there were no representatives from these states. }\end{array}$ \\
\hline $\begin{array}{l}\text { Researcher } \\
\text { Interference }\end{array}$ & Minimal & $\begin{array}{l}\text { There was minimal interference to the work nature and teacher activities by the researchers during } \\
\text { the distribution and collection of questionnaires. }\end{array}$ \\
\hline
\end{tabular}


elements used for this study. Questionnaires were carefully prepared with the anonymity of the respondents safe guarded (See underlying data) ${ }^{16}$. This was ensured as no personal data identifiers were collected. Additionally, an ethics approval was obtained before recruiting participants for the survey. From primary and secondary Malaysian schools, 200 teachers were invited to participate, however only 131 teachers responded. The items were adopted and adapted from various theories and previous studies conducted by Mueller and Dweck $^{6}$, Dweck ${ }^{8}$, Hakak et al. ${ }^{12}$, Eleftheria et al. ${ }^{14}$ and Gipps ${ }^{15}$. They were measured using the 5-point Likert scale, ranging from strongly disagree (1 points) to strongly agree ( 5 points). The odd Likert scale to give the survey respondents a choice to respond neutrally, was included. This was done to obtain evidence about a theme by adding a neutral response option for the respondents to select, should they refrain from selecting an answer from the two extreme choices. The scale offers five answer options. Table 2 depicts the research design components and their respective rationalizations.

\section{Data analysis}

The data for this study was analysed using the SmartPLS 3 software.

\section{Measurement model evaluation}

The measurement model evaluation is required to affirm the reliability and validity of the research model. The data attained from the questionnaires (See underlying data) ${ }^{16}$ were used to structure the measurement model of this study (Figure 1)

Indicator reliability is assessed by ensuring that the factor loadings for each item is above 0.708. However, there is a satisfactory threshold whereby the values of each item do not necessarily have to be above 0.708 . Table 3 affirms that the loadings for each item fall within the satisfactory value, thus indicator reliability is present. Internal consistency reliability is determined by the composite reliability (CR). As depicted in Table 2, the $\mathrm{CR}$ values for each construct are well above

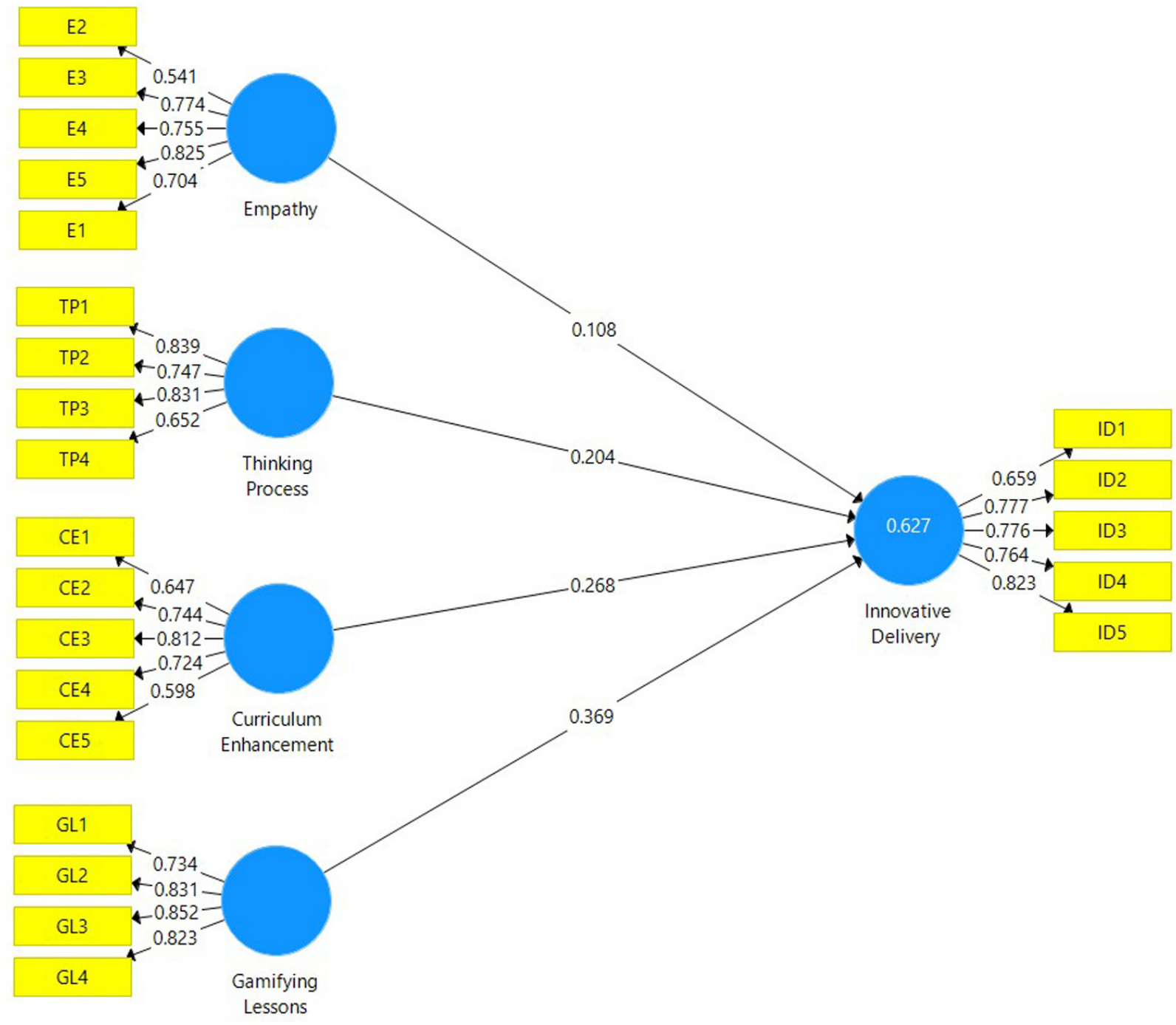

Figure 1. Measurement model depicting the latent variables and their respective indicators. 
Table 3. Factor loadings, Average Variance Extracted and composite reliability of each construct.

\begin{tabular}{|c|c|c|c|c|}
\hline Constructs & Items & Loadings & AVE & CR \\
\hline \multirow[t]{5}{*}{ Curriculum Enhancement } & CE1 & 0.647 & 0.503 & 0.833 \\
\hline & CE2 & 0.744 & & \\
\hline & CE3 & 0.812 & & \\
\hline & CE4 & 0.724 & & \\
\hline & CE4 & 0.598 & & \\
\hline \multirow[t]{5}{*}{ Empathy } & E1 & 0.704 & 0.528 & 0.846 \\
\hline & E2 & 0.541 & & \\
\hline & E3 & 0.774 & & \\
\hline & E4 & 0.755 & & \\
\hline & E5 & 0.825 & & \\
\hline \multirow[t]{4}{*}{ Gamifying Lessons } & GL1 & 0.734 & 0.658 & 0.885 \\
\hline & GL2 & 0.831 & & \\
\hline & GL3 & 0.852 & & \\
\hline & GL4 & 0.823 & & \\
\hline \multirow[t]{4}{*}{ Thinking Process } & TP1 & 0.839 & 0.595 & 0.853 \\
\hline & TP2 & 0.747 & & \\
\hline & TP3 & 0.831 & & \\
\hline & TP4 & 0.652 & & \\
\hline \multirow[t]{5}{*}{ Innovative Delivery } & ID1 & 0.659 & 0.58 & 0.873 \\
\hline & ID2 & 0.777 & & \\
\hline & ID3 & 0.776 & & \\
\hline & ID4 & 0.764 & & \\
\hline & ID5 & 0.823 & & \\
\hline
\end{tabular}

AVE: Average Variance Extracted; CR: Composite Reliability

the 0.70 threshold, hence this affirms that the internal consistency reliability is satisfactory. Convergent validity is determined by the Average Variance Extracted (AVE). The AVE values for each construct must be above 0.50. The AVE for each construct in Table 2 is well above 0.50 and this signifies a satisfactory level of convergent validity for the study.

Discriminant validity is evaluated according to the Fornell and Larcker criterion, whereby an item must show a stronger loading on its own construct when compared to other constructs. Table 4 affirms that each item has a stronger loading on its own construct, therefore, discriminant validity is fulfilled.

\section{Structural model evaluation}

The structural model evaluation is conducted to determine whether the hypotheses are supported by the data attained
Table 4. Discriminant validity matrix.

\begin{tabular}{|c|c|c|c|c|c|}
\hline Constructs & $\mathbf{1}$ & $\mathbf{2}$ & $\mathbf{3}$ & $\mathbf{4}$ & $\mathbf{5}$ \\
\hline Curriculum Enhancement & 0.709 & & & & \\
\hline Empathy & 0.623 & 0.726 & & & \\
\hline Gamifying Lessons & 0.540 & 0.483 & 0.811 & & \\
\hline Innovative Delivery & 0.684 & 0.595 & 0.666 & 0.762 & \\
\hline Thinking Process & 0.701 & 0.697 & 0.492 & 0.657 & 0.771 \\
\hline
\end{tabular}

from the analysis. The structural model depicted in Figure 2 is attained after a non-parametric bootstrapping using a sample of 5,000 was conducted. Before assessing the path coefficient of this study, the coefficient of determination $\left(\mathrm{R}^{2}\right)$ is explained. The value of $\mathrm{R}^{2}$ for this study is 0.627 , which falls under the moderate category. This means that $62.7 \%$ of the total variance in Innovative Delivery is explained by Empathy, Thinking Process, Curriculum Enhancement and Gamifying Lessons.

The path coefficient for this study is depicted in Table 5. For the beta value to make an impact to the research model, the value must be at least 0.1 whereas the t-statistic has to be greater than 1.645 at an alpha level of 0.05 in order for it to be significant. Table 3 confirms that curriculum enhancement, gamifying lessons and thinking process have a significant positive influence in enhancing innovative delivery. However, empathy does not have a significant positive influence in enhancing innovative delivery.

\section{Discussion and conclusion}

The study showed that the thinking process, gamifying lessons, and curriculum enhancement have positive significance for innovative delivery. However, the variable empathy was not supported and did not show a positive significant relationship. The absence of empathy among teachers can affect the educational process adversely. Empathy is a method of associating with others that shows you can comprehend that they are encountering something significant, even though you may not understand precisely how it feels for them ${ }^{17}$. Empathy is an essential advantage that can assist teachers by enhancing the driving factors on students' behaviour. Thus, the link between teachers' empathy and innovative teaching is essential and since the hypothesis for this study pertaining to empathy is not supported, it means that Malaysian teachers in predominantly primary and secondary schools lack empathy, which indirectly creates a large gap or power distance between students and the teachers themselves. This situation further enhances inability to deliver dry and uninteresting teaching and learning material which leads to hatred and disinterest among students in the subject. The current pandemic has made students more productive, independent, and proactive in being responsible for their learning. As such, the overall results of the Sijil Pelajaran Malaysia (SPM) 2020 or the Malaysian Certificate of Education, which is a national examination taken by all 


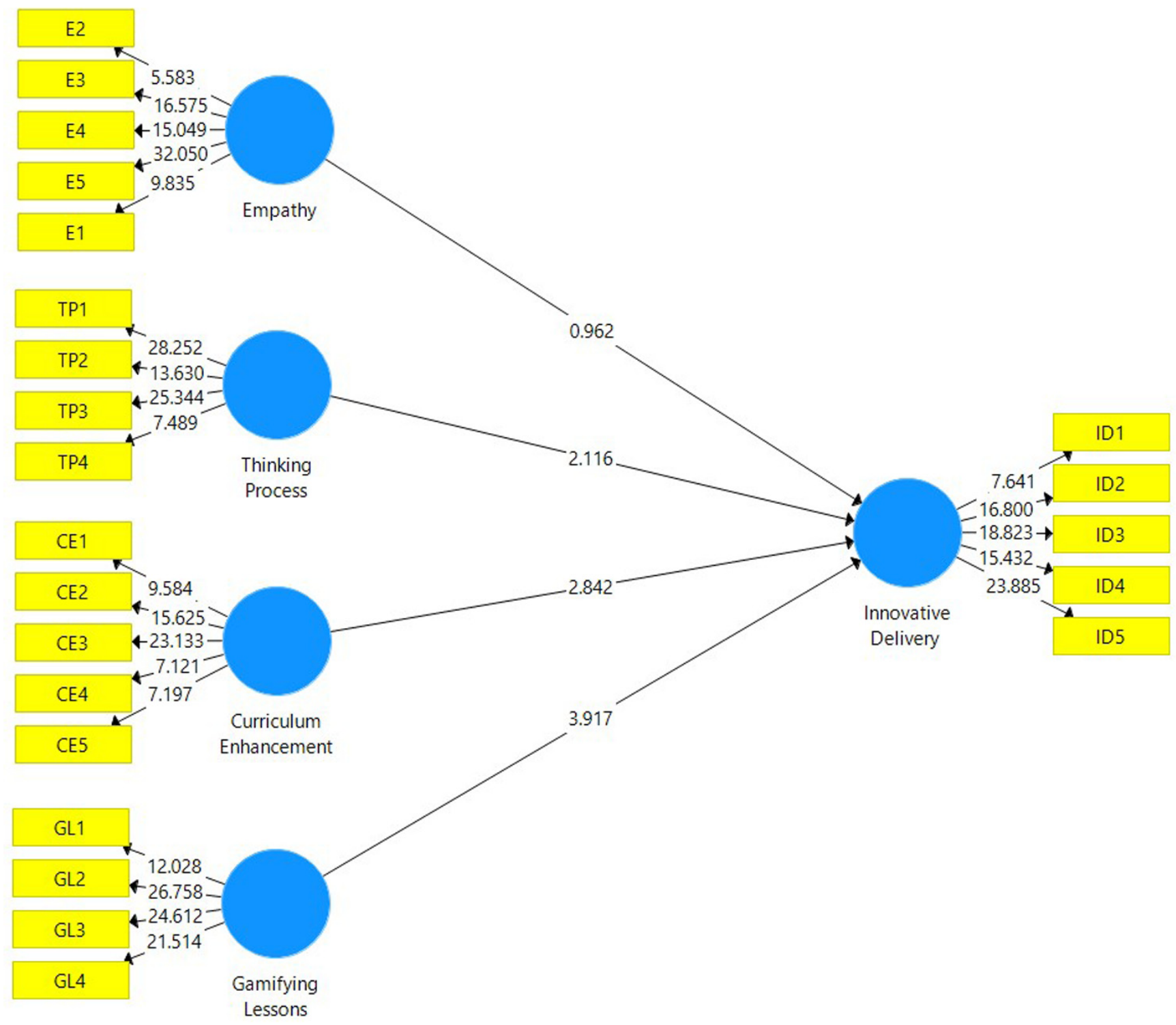

Figure 2. Structural model attained after evaluating the measurement model.

Table 5. Beta value, t-statistics, p-value, and hypothesis decision.

\begin{tabular}{|l|c|c|c|c|}
\hline \multicolumn{1}{|c|}{ Constructs } & Beta & T-Statistic & P-Value & Decision \\
\hline Curriculum Enhancement --> Innovative Delivery & 0.268 & 2.842 & 0.005 & Supported \\
\hline Empathy --> Innovative Delivery & 0.108 & 0.962 & 0.336 & Not Supported \\
\hline Gamifying Lessons --> Innovative Delivery & 0.396 & 3.917 & 0.000 & Supported \\
\hline Thinking Process --> Innovative Delivery & 0.204 & 2.116 & 0.034 & Supported \\
\hline
\end{tabular}

T-value significant at $\geq 1.645$; P-value is significant at $<0.05$ 
fifth-form secondary school students in Malaysia. have shown a sharp rise in passing and grades as compared to previous years ${ }^{18}$. This also indicates that teachers are no longer seen as mere content providers and knowledge givers, but as facilitators and support during difficult times. The lack of empathy among teachers must be addressed if teachers are exposed to DT workshops during their formal training and periodically as part of their learning development programme. The outcome of this study shows the aspects which need to be addressed by the Ministry of Education as well as the teachers in Malaysia. In addition, the outcome of this study may also assist in producing teachers who are well rounded in terms of mastering various teaching skills.

\section{Ethics approval}

The Research Ethics Committee (REC) of Multimedia University has granted the ethics approval for this research with the approval number EA2232021.

\section{Data availability}

Underlying data

Figshare: Enhancing innovative delivery in schools using design thinking

DOI: $10.6084 / \mathrm{m} 9$. figshare. $14871879^{16}$.
This project contains the following underlying data:

Data file 1. The data attained from the questionnaire. This file is to be opened using the SPSS software.

Data file 2. Questionnaire used for this research.

Data are available under the terms of the Creative Commons Zero "No rights reserved" data waiver (CCO 1.0 Public domain dedication).

\section{Author contributions}

Sharmini Gopinathan was responsible for the conceptualization, supervision, methodology and data analysis. Anisha Haveena Kaur assisted in the conceptualization, investigation, and data analysis. R. Kanesaraj Ramasamy provided resources for this study and explained the findings of the research. Murali Raman also provided the resources for the study (specifically for Design Thinking) and assisted in the direction of this research. All authors were part of the writing process. Sharmini and Anisha took on the responsibility to address comments by the reviewers.

\section{Acknowledgments}

The authors would like to express their gratitude towards the respondents (teachers) who participated in the survey.

\section{References}

1. Oxford University Press: Design. Retrieved from Lexico: 2021 Reference Source

2. Oxford University Press: Thinking. Retrieved from Lexico: 2021 Reference Source

3. Naiman L: Design Thinking as a Strategy for Innovation. Retrieved from The European Business Review: 2019. Reference Source

4. Plattner H, Meinel C, Leifer L: Design Thinking: Understand-Improve-Apply. Heidelberg: Springer, 2011. Publisher Full Text

5. Warren CA: Empathy, Teacher Dispositions, and Preparation for Culturally Responsive Pedagogy. J Teach Educ. 2017; 69(2): 169-183. Publisher Full Text

6. Mueller CM, Dweck CS: Praise for intelligence can undermine children's motivation and performance. J Pers Soc Psychol. 1998; 75(1): 33-52. PubMed Abstract | Publisher Full Text

7. Burnett PC: Teacher Praise and Feedback and Students' Perceptions of the Classroom Environment. Educational Psychology: An International Journal of Experimental Educational Psychology. 2002; 22(1): 5-16. Publisher Full Text

8. Dweck C: Mindset: The New Psychology of Success. New York: Ballantine Books, 2007. Reference Source

9. Anderson RT, Neri L: Reliability-Centered Maintenance: Management and Engineering Methods. Essex: Elsevier Science Publishers Ltd, 1990. Publisher Full Text

10. Cambridge: Developing the Cambridge learner attributes. Retrieved from Cambridge International: 2011. Reference Source
11. Gopinathan S, Raman M, Subbarao A, et al:: The Role of Blended Learnning Technologies in Enhancing Student Engagement in Theory Dominant Subjects. International Journal of Creative Multimedia. 2020; 1(1): 64-69. Publisher Full Text

12. Hakak S, Noor NFM, Ayub MN, et al.: Cloud-assisted gamification for education and learning - Recent advances and challenges. Computers \& Electrical Engineering. 2019; 74: 22-34. Publisher Full Text

13. Nah FFH, Zeng Q, Telaprolu VR, et al.: Gamification of Education: A Review of Literature. International Conference on HCI in Business. 2014; 8527: 401-409. Publisher Full Text

14. Eleftheria CA, Charikleia P, Iason CG, et al:: An innovative augmented reality educational platform using Gamification to enhance lifelong learning and cultural education. IISA 2013: Fourth International Conference on Information, Intelligence, Systems and Applications. Piraeus: Institute of Electrical and Electronics Engineers (IEEE), 2013. Publisher Full Text

15. Gipps C: Beyond Testing: Towards a Theory of Educational Assessment. London: Routledge, 2011. Reference Source

16. Gopinathan S, Kaur AH, Ramasamy RK, et al.: SPSS Survey Data for Enhancing Innovative Delivery Using Design Thinking. figshare. Dataset. 2021 https://doi.org/10.6084/m9.figshare.14871879.v1

17. Peck NF, Maude SP, Brotherson MJ: Understanding preschool teachers' perspectives on empathy: A qualitative inquiry. Early Child Educ J. 2015; 43(3): 169-79. Publisher Full Text

18. Chung N: $\mathbf{2 0 2 0}$ SPM results best in past $\mathbf{5}$ years. Retrieved from Free Malaysia Today, 2021. Reference Source 


\section{Open Peer Review}

\section{Current Peer Review Status: ? ?}

\section{Version 1}

Reviewer Report 15 November 2021

https://doi.org/10.5256/f1000research.76468.r95938

(C) 2021 Samsudin A. This is an open access peer review report distributed under the terms of the Creative Commons Attribution License, which permits unrestricted use, distribution, and reproduction in any medium, provided the original work is properly cited.

\section{Achmad Samsudin}

Department of Physics Education, Universitas Pendidikan Indonesia, Bandung, Indonesia

\section{$\underline{\text { Abstract }}$}

Explain in the abstract section the research questions used and the result. Describe the number of teachers for each school (primary and secondary schools). Describe what survey instruments were used? Open/close-ended, how many questions, using a Likert scale or something like that, etc.

\section{Introduction}

Is there any previous research that discusses something similar? And what is the novelty of this research? Explain in this section.

Add citations for your opinion. Is it necessary to use innovative delivery to benefit from learning outcomes?

In the fulcrum of the study's objectives, this section should serve as an answer to a research question, but why are the numbers different? It should only be the same number of research questions.

\section{Methods}

Put the design in the abstract.

For respondents, describe the number of teachers for each school (primary and secondary schools).

Explain why the SmartPLS 3 software is used in this study. If necessary add citations to strengthen it.

Note in Table 1, there are 5 DT Phases (of course this section is an indicator in this study). However, why in Figure 1 do only 4 of the 5 phases exist? The missing piece is "Prototype", why is that?

Same for Figure 2, why do only 4 of the 5 phases exist? The missing piece is "Prototype", why is that? 
Is the work clearly and accurately presented and does it cite the current literature? Yes

Is the study design appropriate and is the work technically sound?

Yes

Are sufficient details of methods and analysis provided to allow replication by others? Partly

If applicable, is the statistical analysis and its interpretation appropriate? Yes

Are all the source data underlying the results available to ensure full reproducibility? Yes

Are the conclusions drawn adequately supported by the results?

Yes

Competing Interests: No competing interests were disclosed.

Reviewer Expertise: Science education, conception, conceptual change, misconception in physics, development of models, media, and instruments

I confirm that I have read this submission and believe that I have an appropriate level of expertise to confirm that it is of an acceptable scientific standard, however I have significant reservations, as outlined above.

\section{Author Response 23 Nov 2021}

Sharmini Gopinathan, Multimedia University, Cyberjaya, Malaysia

\section{Abstract}

1. Explain in the abstract section the research questions used and the result.

- Included in the abstract, as recommended.

2. Describe the number of teachers for each school (primary and secondary schools).

- The number of teachers for each school has been added, as recommended. 61 of the respondents are primary school teachers and 70 of the respondents are secondary school teachers.

3. Describe what survey instruments were used? Open/close-ended, how many questions, using a Likert scale or something like that, etc. 
- The description of the instrument has been added. Questionnaire was used and there were 23 close-ended questions. A 5-point Likert scale was used.

\section{Introduction}

1. Is there any previous research that discusses something similar? And what is the novelty of this research? Explain in this section. Add citations for your opinion.

- We have included an explanation about DT in the education context, specifically in schools, whereby there is limited empirical research.

2. Is it necessary to use innovative delivery to benefit from learning outcomes?

- Yes, this is much needed in the Malaysian context, especially with the sudden transition from face-to-face teaching to online teaching due to the pandemic. Teachers and schools are finding new and innovative ways to deliver their learning outcomes.

3. In the fulcrum of the study's objectives, this section should serve as an answer to a research question, but why are the numbers different? It should only be the same number of research questions.

- We have amended the research objectives to suit the research questions. The research objectives are as follows:

1. To determine if DT in the form of empathy leads to innovative delivery of curriculum.

2. To examine if DT can lead to new forms of thinking processes, gamified lessons and curriculum enhancement, thus leading to innovative delivery of curriculum.

\section{Methods}

1. Put the design in the abstract.

- Added. Included the use of questionnaire, number of questions and the Likert scale used.

2. For respondents, describe the number of teachers for each school (primary and secondary schools).

- The number of teachers for each school have been added, as recommended. 61 of the respondents are primary school teachers and 70 of the respondents are secondary school teachers.

3. Explain why the SmartPLS 3 software is used in this study. If necessary add citations to strengthen it.

- SmartPLS 3 software was used as it is able to analyse inter-relationships between variables, whereby single/multiple regressions can be stated (Hair et al., 2011). 
4. Note in Table 1, there are 5 DT Phases (of course this section is an indicator in this study). However, why in Figure 1 do only 4 of the 5 phases exist? The missing piece is "Prototype", why is that? Same for Figure 2, why do only 4 of the 5 phases exist? The missing piece is "Prototype", why is that?

- As per the Introduction section, "Prototype" falls under the sub-section "Gamifying Lessons". We have described it as such: "Prototyping in DT leads to a new form of learning, which in this context refers to gamification".

References

Hair, J. F., Ringle, C. M., \& Sarstedt, M. (2011). PLS-SEM: Indeed a silver bullet. Journal of Marketing theory and Practice, 19(2), 139-152. DOI: 10.2753/MTP1069-6679190202

Competing Interests: No competing interests were disclosed.

Reviewer Report 26 October 2021

https://doi.org/10.5256/f1000research.76468.r95936

(c) 2021 Carvalho P. This is an open access peer review report distributed under the terms of the Creative Commons Attribution License, which permits unrestricted use, distribution, and reproduction in any medium, provided the original work is properly cited.

\section{Paulo SImeão Carvalho}

Physics and Astronomy Department, Science Education Unit, Faculty of Sciences, University of Porto, Porto, Portugal

The paper describes the role of design thinking that can lead to innovative teaching among teachers. In particular, it presents a study that seeks how several variables such as empathy, thinking process, gamifying lessons and curriculum enhancement, may have positive significance for innovative delivery. The study targeted 131 teachers from primary and secondary schools in Malaysia.

I find this paper has great interest for teachers, although it concerns only Malaysian ones. The case cannot be extrapolated to other countries, but undoubtedly points out to real educational problems that should be seen very seriously by decision makers.

Concerning the sample, it is not clear how many of those 131 teachers were from primary school and secondary school. As far as I know, the teaching goals, the contact hours and the involvement of teachers with their students may not be exactly the same for both categories of teacher, therefore the authors should provide separate analysis for both samples - even if, at the end, they conclude the results are equivalent.

There are some issues that could be clarified by the authors (page numbers refer to the pdf 
version):

1. In page 3 , line 4 (Introduction), left column, the acronym VUCA is not used in the paper. I suggest to remove it, unless there is a specific reason to keep it.

2. Page 4, line 4, left column: I would say that not only collaborative, but also cooperative learning should be recommended, as the latter involves students in the responsibility for finding solutions to the problems.

3. Page 5, line 13, right column: instead of "the loadings for each item fall within the satisfactory value", I suggest it should be added "for the majority of items" because as the authors recognize, there are some items that do not fulfill that condition.

4. Page 4, figure 1, empathy variables: why is the sequence, from top to bottom, different from the other design components? i.e., why not E1; E2; E3; E4; E5 ? The same comment applies to Figure 2.

5. Page 6 , line 12 , right column: alpha value, or p-value?

6. Page 6, line 32-33, right column: the sentence "Malaysian teachers in predominantly primary and secondary schools lack empathy" is somehow exaggerated. This study is based only in 131 responses, which do not represent, in any way, Malaysian teachers. The authors cannot make such a generalization. This sentence MUST be reformulated to the local validity of this study.

7. Page 6, line 36-38, right column: I don't see a direct correlation between the results obtained and the conclusion that "This situation further enhances inability to deliver dry and uninteresting teaching and learning material". The authors should discuss better how they figure out such a correlation derived from their definition of Empathy. Their extrapolation is very broad and I don't think it has support in this investigation. Perhaps the authors want to rephrase it as a possibility that might occur, but not as an affirmative statement.

8. Page 6, table 2, line 5: item "CE4" seems to be "CE5".

9. Finally, the reference list seems adequate to the study reported, and the English is of high quality.

In conclusion:

I believe the paper is interesting for discussion about the influence of several parameters to innovative delivery in schools, taking for a particular example primary and secondary teachers in Malaysia. However, some topics could be clarified and generalizations should be avoided because the study is not vast enough.

So, I recommend this paper for indexing, but the authors must correct some errors and clarify the items mentioned first.

Is the work clearly and accurately presented and does it cite the current literature? 
Yes

Is the study design appropriate and is the work technically sound?

Yes

Are sufficient details of methods and analysis provided to allow replication by others? Yes

If applicable, is the statistical analysis and its interpretation appropriate?

I cannot comment. A qualified statistician is required.

Are all the source data underlying the results available to ensure full reproducibility? Yes

Are the conclusions drawn adequately supported by the results?

Partly

Competing Interests: No competing interests were disclosed.

Reviewer Expertise: Physics education; teacher training in phusics; digital educational resources; experimental work

I confirm that I have read this submission and believe that I have an appropriate level of expertise to confirm that it is of an acceptable scientific standard, however I have significant reservations, as outlined above.

Author Response 23 Nov 2021

Sharmini Gopinathan, Multimedia University, Cyberjaya, Malaysia

(Page numbers refer to the pdf version of the article)

1. In page 3 , line 4 (Introduction), left column, the acronym VUCA is not used in the paper. I suggest to remove it, unless there is a specific reason to keep it.

-The acronym VUCA has been removed as it is not used in the paper.

2. Page 4, line 4, left column: I would say that not only collaborative, but also cooperative learning should be recommended, as the latter involves students in the responsibility for finding solutions to the problems.

- A very good recommendation by the reviewer. However, as the statement was attained from a citation, we are not able to add it in the sentence as it will not reflect what was originally interpreted/meant by the author (of the citation). We shall take note of cooperative learning for future studies.

3. Page 5, line 13, right column: instead of "the loadings for each item fall within the 
satisfactory value", I suggest it should be added "for the majority of items" because as the authors recognize, there are some items that do not fulfil that condition.

- "Each item" has been replaced with "for the majority of items", as recommended.

4. Page 4, figure 1, empathy variables: why is the sequence, from top to bottom, different from the other design components? i.e., why not E1; E2; E3; E4; E5 ? The same comment applies to Figure 2 .

- The sequence was automatically generated by the SmartPLS 3.0 software. As the figures were directly taken from the (measurement and structural) models generated by the software, we have decided to not alter it and retain the sequence the way it is.

5. Page 6, line 12, right column: alpha value, or p-value?

- Alpha value (significance level).

6. Page 6, line 32-33, right column: the sentence "Malaysian teachers in predominantly primary and secondary schools lack empathy" is somehow exaggerated. This study is based only in 131 responses, which do not represent, in any way, Malaysian teachers. The authors cannot make such a generalization. This sentence MUST be reformulated to the local validity of this study.

- The sentence has been changed to "Thus, the link between teachers' empathy and innovative teaching is essential and since the hypothesis for this study pertaining to empathy is not supported, it means that the Malaysian teachers who participated in this study predominantly lack empathy, which indirectly creates a large gap or power distance between students and the teachers themselves". This was done to avoid generalisation of the whole population.

7. Page 6, line 36-38, right column: I don't see a direct correlation between the results obtained and the conclusion that "This situation further enhances inability to deliver dry and uninteresting teaching and learning material". The authors should discuss better how they figure out such a correlation derived from their definition of Empathy. Their extrapolation is very broad and I don't think it has support in this investigation. Perhaps the authors want to rephrase it as a possibility that might occur, but not as an affirmative statement.

- Rephrased as suggested by the reviewer.

8. Page 6, table 2, line 5: item "CE4" seems to be "CE5".

- CE4 has been changed to CE5.

9. Finally, the reference list seems adequate to the study reported, and the English is of high quality.

- Thank you. 
10. Concerning the sample, it is not clear how many of those 131 teachers were from primary school and secondary school. As far as I know, the teaching goals, the contact hours and the involvement of teachers with their students may not be exactly the same for both categories of teacher, therefore the authors should provide separate analysis for both samples - even if, at the end, they conclude the results are equivalent.

- 61 of the respondents are primary school teachers and the remaining 70 respondents are secondary school teachers. As this is not a comparison study between primary and secondary school teachers, we have decided to retain the current analysis as is it.

Competing Interests: No competing interests were disclosed.

The benefits of publishing with F1000Research:

- Your article is published within days, with no editorial bias

- You can publish traditional articles, null/negative results, case reports, data notes and more

- The peer review process is transparent and collaborative

- Your article is indexed in PubMed after passing peer review

- Dedicated customer support at every stage

For pre-submission enquiries, contact research@f1000.com 